\title{
FACILITATION OF LORDOSIS IN OVARIECTOMIZED RATS BY INTRACEREBRAL PROGESTERONE IMPLANTS
}

\section{J. BRADLEY POWERS}

Neuroscience Laboratory, University of Michigan, Ann Arbor, Mich. 48104 (U.S.A.)

(Accepted July 4th, 1972)

\section{INTRODUCTION}

Sexual receptivity in female mammals occurs following appropriate hormonal stimulation ${ }^{60}$. In many species, the combined action of estrogen and progesterone is more effective than estrogen alone ${ }^{6,16,41}$. A variety of behavioral, neuroanatomical and electrophysiological investigations suggest that these ovarian hormones affect sexual behavior by acting on the central nervous system ${ }^{30}$ although effects on peripheral tissues might also be important. Estrogen may act primarily in the medial preoptic area (MPOA) to stimulate receptivity because chronic estradiol implants most effectively reinstate the lordosis reflex in ovariectomized females ${ }^{29}$ when placed in this region. This is consistent with the selective accumulation of estradiol by cells in the MPOA although other sites within the central nervous system also show affinity for this hormone ${ }^{1,3,52}$.

The quantities of estradiol secreted by rats displaying 4-day estrous cycles are not sufficient to induce behavioral estrus; the subsequent action of progresterone is essential ${ }^{41}$. The brain sites at which progesterone might act to facilitate receptivity have until recently remained unexplored. One early study demonstrated that bilateral implants of estradiol on one side and a progesterone pellet of over $1 \mathrm{~mm}$ diameter on the other induced female sexual behavior when placed either in the preopticanterior hypothalamic region or in the middle hypothalamus ${ }^{31}$. Because considerable diffusion of hormone may have occurred due to the large surface area of the progesterone pellet, it was not possible to specify regions of high progesterone sensitivity. Early studies of progesterone uptake by brain tissue indicated that selective accumulation of progesterone by subregions within the hypothalamus did not occur 48,49 . More recently the mesencephalic reticular formation has been implicated as a critical site for progesterone action because hormone implants in that region were effective in facilitating sexual receptivity whereas similar implants in various hypothalamic areas were not ${ }^{46}$. Recent biochemical investigations demonstrating considerable uptake of radioactivity in the rat midbrain following injection of $\left[{ }^{3} \mathrm{H}\right]$ progesterone are consistent with these behavioral results ${ }^{58,58}$. 
Prior to the study reported here, the present investigator had attempted systematically to explore the hormone sensitivity of various brain sites by assessing sexual receptivity in estrogen-primed female rats after they had received bilateral implants of progesterone ${ }^{42}$. In this first study the medial basal hypothalamus including the ventromedial and arcuate nuclei appeared most responsive to progesterone; the sensitivity of medial preoptic cells was minimal and the lateral hypothalamus-medial forebrain bundle region showed no progesterone responsiveness at all. Since these results and the concurrent findings of Ross et al. ${ }^{46}$ were contradictory, it seemed important to establish more reliable evidence concerning the brain sites at which progesterone could facilitate female sexual behavior.

\section{MATERIALS AND METHODS}

Adult, Long-Evans rats obtained from Simonsen Laboratories, Inc., Gilroy, Calif. were housed individually and provided with food and water ad libitum in a room illuminated daily from midnight to noon. Prior to behavioral testing, animals were ovariectomized and bilaterally implanted with cannulae aimed for either the medial basal hypothalamus $(\mathrm{MBH})$ or the mesencephalic reticular formation (MRF). Both surgical procedures were carried out under anesthesia consisting of chloral hydrate, pentobarbital and magnesium sulfate (Equi-Thesin, Jensen-Salsbery Laboratories, Kansas City, Mo.).

The cannula system used consisted of an outer guide shaft permanently attached to the skull and a removable inner cannula which could be inserted and withdrawn easily in awake animals. Inner and outer cannulae were made of 27 - and 21-gauge stainless steel hypodermic tubing, respectively. The inner cannula had a small stop on its protruding end to assure that when placed into the outer cannula, the tips of both the inner and outer tubing within the brain would be flush. A plastic cap could be screwed down over the entire system to hold the inner cannula firmly in place.

Outer cannula tips were aimed for either the MBH or MRF. The following placement coordinates were used with the skull flat between bregma and lambda representing $\mathrm{mm}$ behind bregma, to the left and right of the midline, and below the skull surface: $\mathrm{MBH}, 3.0,2.5$ and 9.0; MRF, 5.5, 2.5 and 6.5. For both placements the cannulae tips were angled from the vertical towards the midline by $12.5^{\circ}$ for $\mathrm{MBH}$ and $10^{\circ}$ for MRF animals. This allowed a convenient separation between the exposed portions of the cannula assemblies above the skull but was calculated to position the tips within $0.5 \mathrm{~mm}$ of the midline within the brain.

Sexual receptivity was quantitatively evaluated by scoring the lordosis responses elicited by vigorous Long-Evans male rats previously adapted to semi-circular mating arenas ( $76 \mathrm{~cm}$ diameter and $40 \mathrm{~cm}$ in height and width). A male's behavior had to consist of a discrete mount with palpation of the flanks and rapid pelvic thrusting before the female's response was scored. The quality of each lordosis was rated on a scale from 0 to $3 ; 0=$ no concave arching of the back; 1,2 and $3=$ slight, moderate and full arching, respectively. The postures associated with these scores have recently been

Brain Research, 48 (1972) 311-325 
illustrated ${ }^{15}$. Other behaviors occasionally displayed by estrous females such as darting, hopping and head-shaking were not quantified. Receptivity tests were terminated after response scores to 10 adequate mounts by the male had been obtained. In some instances testing was stopped after 6 responses if all these were scored as either 3 or 0 . Testing was also discontinued if the stud male ejaculated on or after the 5 th response. If ejaculation occurred before this, testing was resumed in 5-10 min. For each behavior test the mean response score was used as the receptivity index.

During tests in which hormones were placed directly into the brain, inner cannulae contained either progesterone or cholesterol (Sigma Chemical Co., St. Louis, Mo.). At all other times empty inner cannulae were left in place to serve as plugs. Prior to hormone implants, crystals of the appropriate substance were gently tamped at least 30 times into the lumen of the inner cannulae ( $200 \mu \mathrm{m}$ in diameter). Each cannula was cleaned and microscopically examined to assure that the test substance was contained within the lumen and not exposed on the adjacent tubing walls. When cannulae were reused, old hormone was removed by heating the cannulae tips over an alcohol burner after an overnight soaking in methanol; new hormone was then loaded according to the procedure described above.

The amount of progesterone tamped into each inner cannula was not determined but based on the measures of others ${ }^{9}$, it can be estimated to be considerably less than $10 \mu \mathrm{g}$. After each stimulation period the cannulae were visually inspected for evidence of remaining hormone. In all cases, the tips appeared full and there were no obvious indications that sizable amounts of hormone had diffused from the cannulae. Thus only the small fraction of progesterone exposed at the cannulae tips was able to stimulate neural tissue. Cholesterol was used to control for general steroid effects unrelated to the biological properties of progesterone and to control for non-specific stress factors associated with the cannula insertion procedures.

When hormones were injected subcutaneously (s.c.), estradiol benzoate (EB) and progesterone $(P)$ were dissolved in sesame oil (Progynon Benzoate and Proluton, Schering, Bloomfield, N. J.). The volume of $P$ administered was always $0.1 \mathrm{ml}$; EB volume in $\mathrm{ml}$ was equal to $1 / 2$ the body wt. in $\mathrm{kg}$.

Shortly after the outer cannulae had been permanently implanted, a series of preliminary tests was carried out over the next 3 months to explore a variety of procedures for evaluating the effects of intracerebral progesterone on estrous behavior. Because female rats can become receptive after estrogen alone when this hormone is repeatedly injected, a design utilizing a minimum of estrogen injections was considered most desirable. The testing paradigm finally adopted is illustrated in Fig. 1. The important features of this paradigm consist of an initial injection of EB to achieve sufficient estrogen priming followed by a series of receptivity tests within the next $54 \mathrm{~h}$ both before and after progesterone was either placed in the brain or administered systemically. The insertion of progesterone or cholesterol into the brain was always combined with a subthreshold quantity of progesterone injected subcutaneously. This dose $(100 \mu \mathrm{g})$ in the absence of any brain implant was shown previously to have insignificant facilitating effects on estrous behavior ${ }^{44}$. The use of a combined implant and subthreshold injection of progesterone was found to increase the ease with which 


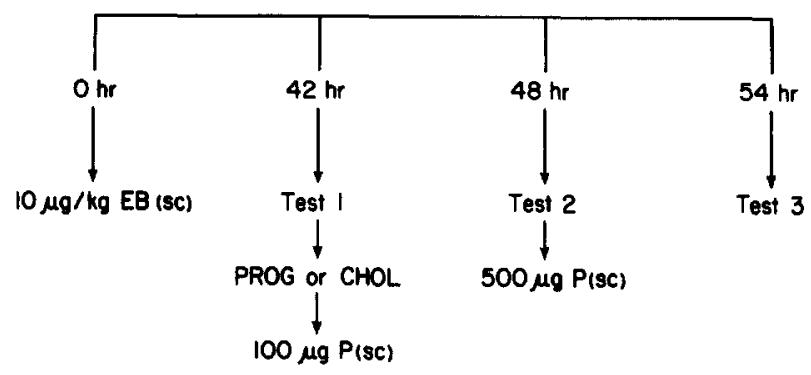

Fig. 1. Experimental paradigm used for determining the effects of intracerebral progesterone on sexual receptivity in ovariectomized female rats. Test 1,2 and 3 assessed the quality of estrous behavior at the times indicated. $\mathrm{EB}$, estradiol benzoate; $\mathrm{P}$, progesterone (EB and $\mathrm{P}$ were dissolved in sesame oil vehicle); sc, subcutaneous injection; PROG or CHOL, crystalline progesterone or cholesterol in brain.

the behavioral effects of intracerebral progesterone could be demonstrated. Prior to the final behavior test $500 \mu \mathrm{g}$ of progesterone was injected systemically. This quantity of progesterone readily induces receptive behavior in females appropriately primed with estrogen. This sequence of 3 receptivity tests was designed (a) to assess the occurrence of lordosis following the estrogen alone (test 1 ), (b) to measure any facilitation of behavioral estrus due to the brain implants (test 2), and (c) to assure that suprathreshold quantities of progesterone $(500 \mu \mathrm{g})$ when administered systemically would induce receptive behavior (test 3 ). The latter test was particularly important in cases where test 1 and 2 gave low receptivity scores. A high test 3 score in such cases indicated that females were properly estrogen-primed and could respond to systemic progesterone but that the particular central sites exposed to the progesterone implant were insensitive to its effects on receptive behavior.

All females were tested twice at 14-day intervals under the sequence illustrated in Fig. 1. For $1 / 2$ the females in both the MBH and MRF cannula groups, progesterone was inserted during the first series and cholesterol during the second; this sequence was reversed for the remaining animals. The cannulae loaded with either progesterone or cholesterol were inserted immediately after test 1 and were withdrawn and replaced with empty plugs following test 2 . Thus the brain was exposed to hormone in bilateral cannulae for a 6 -h period which corresponds to the time interval which is optimal for inducing behavioral effects following systemic administration of progesterone $^{32}$.

After the completion of behavioral testing, rats were killed with an overdose of sodium pentobarbital and perfused through the heart with physiological saline and $10 \%$ formalin. Frozen sections were cut at $80 \mu \mathrm{m}$ and stained with cresylecht violet to verify the anatomical localization of cannula placements.

RESULTS

Progesterone facilitated the display of estrous behavior when placed in the medial basal hypothalamus but not when implanted in the mesencephalic reticular for-

Brain Research, 48 (1972) 311-325 
TABLE I

RECEPTIVITY SCORES OF OVARIECTOMIZED FEMALE RATS DURING TESTS TO ASSESS THE FACILITATORY EFFECTS OF INTRACEREBRAL PROGESTERONE ON ESTROUS BEHAVIOR (MEAN \pm S.D.)

Estradiol benzoate (EB) and progesterone (P) when injected subcutaneously (s.c.) were dissolved in sesame oil. When implanted into the medial basal hypothalamus $(\mathrm{MBH})$ or mesencephalic reticular formation (MRF), progesterone (PROG) and cholesterol (CHOL) were in crystalline form.

\begin{tabular}{|c|c|c|c|c|}
\hline & \multirow[t]{2}{*}{ Implant } & \multicolumn{3}{|l|}{ Tests } \\
\hline & & (1) $E B$ (s.c.) & $\begin{array}{l}\text { (2) Brain implant } \\
+100 \mu g P \text { (s.c.) }\end{array}$ & (3) $500 \mu g P$ (s.c.) \\
\hline $\mathrm{MBH}(\mathrm{n}=16)$ & $\begin{array}{l}\text { PROG } \\
\text { CHOL }\end{array}$ & $\begin{array}{l}0.75 \pm 0.69 \\
0.90 \pm 0.86\end{array}$ & $\begin{array}{l}2.1 \pm 0.77 \\
1.72 \pm 0.70\end{array}$ & $\begin{array}{l}1.91 \pm 0.76 \\
2.3 \pm 0.45\end{array}$ \\
\hline MRF $(n=11)$ & $\begin{array}{l}\text { PROG } \\
\text { CHOL }\end{array}$ & $\begin{array}{l}0.37 \pm 0.60 \\
0.37 \pm 0.53\end{array}$ & $\begin{array}{l}0.94 \pm 0.71 \\
1.3 \pm 0.98\end{array}$ & $\begin{array}{l}1.75 \pm 0.81 \\
2.15 \pm 0.92\end{array}$ \\
\hline
\end{tabular}

mation. Table I provides the mean receptivity scores on all tests for $16 \mathrm{MBH}$ and 11 MRF females. Only two animals (one MBH, one MRF) failed to respond on test 3 after the standard sc progesterone injection and consequently they were discarded. Because Table I includes results from both effective and ineffective cannula placements the variability in scores is much greater than will be apparent after the histological analysis of cannula sites is presented.

In order to compare the effects of brain progesterone among the $\mathrm{MBH}$ and MRF females, a facilitation score (FS) was derived for each animal. This was defined as the numerical difference between test 2 and test 1 receptivity measures (Fig. 1) which indicated the extent to which the brain implant plus the subthreshold progesterone injection facilitated behavioral estrus (test 2) beyond that which was already present after the estrogen injection alone (test 1). For any animal both a progesterone FS and a cholesterol FS could be determined from the receptivity scores measured during the two testing sequences. By subtracting the cholesterol FS from the progesterone FS a corrected progesterone score was obtained for each female representing that portion of the progesterone FS which was due to the local effects of progesterone in the brain and unrelated to non-specific factors associated with stressing rats during insertion of cannulae or to the subcutaneous injection of $100 \mu \mathrm{g}$ progesterone. The mean corrected progesterone scores were 0.79 and 0.23 for the MBH and MRF groups, respectively, $(P<0.025$, Mann-Whitney $U$ test) indicating that on the average, the amount of facilitation attributable to the implanted progesterone was significantly greater in the MBH than in the MRF females.

Only 3 of the $16 \mathrm{MBH}$ animals failed to show some facilitation of sexual behavior after the progesterone implants. Among the remaining 13 females, brain progesterone enhanced lordosis to variable degrees. To determine whether this response facilitation was reliably greater than that following cholesterol, the differences between the progesterone FS and cholesterol FS were evaluated (Fig. 2) and found to be highly significant $(P<0.005$, Wilcoxon $\mathrm{T}$ test $)$. A comparable analysis for the 7 


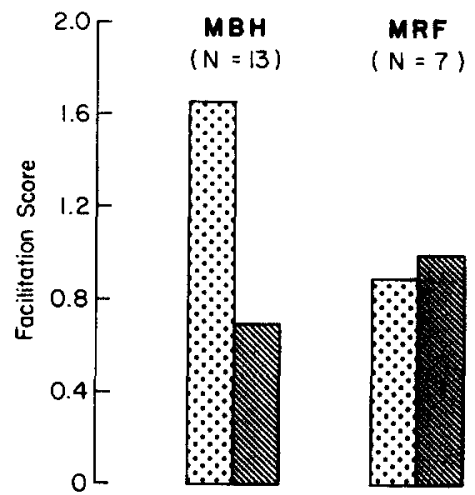

Fig. 2. Mean brain progesterone (stippled) and cholesterol (striped) facilitation scores (cf. text) for female rats with bilateral cannulae in the medial basal hypothalamus (MBH) or mesencephalic reticular formation (MRF).

of $11 \mathrm{MRF}$ animals which showed some progesterone facilitation indicated that this effect was non-significant.

Females in both the MBH and MRF groups displayed comparable levels of receptivity following the standard injection of progesterone (Fig. 1, test 3). However for all subjects these behavioral levels were lower during sequences when the progesterone injection was preceded by a progesterone implant than when preceded by a cholesterol implant (Table 1). Thus when progesterone was placed in either the $\mathrm{MBH}$ or MRF it tended to depress subsequent responsiveness to systemically administered progesterone but within neither group did this effect attain statistical significance.

The cannulae of $\mathrm{MBH}$ females displaying facilitation of behavioral estrus were generally located in or close to the ventromedial (VM) and arcuate (ARC) nuclei of the hypothalamus. Fig. 3 depicts these placements and indicates the associated extent of behavior facilitation. The corrected progesterone score for each animal was categorized as low (0.0-0.5), moderate (0.6-1.0), or high (1.1 and above). All females with cannulae directly in the VM or ARC had corrected scores between 1.3 and 1.5 (Fig. 3 , No. $345,329,285,277,333$ ). Unfortunately the highest score (1.9) was displayed by an animal for which no histology was available. In the majority of cases cannulae located either dorsally, laterally or posteriorly to the VM-ARC region were associated with moderate or low progesterone scores. Only one female with cannulae outside the VM-ARC area in the medial mammillary nucleus showed high progesterone responsiveness (Fig. 3, No. 356).

MRF implants are shown in Fig. 4. Most placements were within the reticular formation at the coronal level of the red nucleus; two were adjacent to the interstitial nucleus of Cajal (Fig. 4, No. 322, 373) and one was in the vicinity of the lateral central gray and nucleus Darkschewitsch (Fig. 4, No. 289). The one subject with a high progesterone score (Fig. 4, No. 372) had its cannulae about $1 \mathrm{~mm}$ lateral to the central gray but other placements in this same general region elicited low progesterone scores.

Brain Research, 48 (1972) 311-325 


\section{DISCUSSION}

Small, bilateral implants of progesterone in the medial basal hypothalamus facilitate sexual receptivity in estrogen-primed, ovariectomized rats. These results confirm and extend earlier work in which this region was found much more responsive to progesterone than either the medial preoptic area or the lateral hypothalamus ${ }^{42}$. In the present investigation, brain implants of hormone were always combined with subthreshold systemic injections of progesterone. The degree to which progesterone administered systemically participated in the facilitation of estrus was not quantified. If it is assumed that a variety of neural regions may be responsive to progesterone, this procedure assured that these regions were at least minimally exposed to progesterone stimulation. Because a large number of sites in the central nervous system remain to be tested for progesterone sensitivity, it would be premature to assert that the $\mathrm{MBH}$ constitutes a focal center which mediates the action of progesterone on estrous behavior.

Two major problems must be considered in assessing the results of hormone implant studies. These concern the extent to which behavioral effects might be caused by (a) entry of hormone into the ventricular system or systemic circulation, and (b) the possible diffusion of hormone throughout a large zone of neuropil. In the present study the majority of animals with effective placements in the VM-ARC region had one or both cannulae close to the third ventricle (Fig. 3). Conceivably progesterone could have diffused through the ependymal lining of the ventricle and exerted its behavioral effects by diffusion back into the CNS at sites remote from the medial basal hypothalamus. Although such ventricular diffusion effects have been demonstrated for adrenal steroids ${ }^{18}$, this possibility is unlikely here because a number of rats in which progesterone did not facilitate receptivity had cannula placements equally close to the third ventricle. In addition there was no indication that subjects in which one cannula had actually penetrated the ventricular wall were unusually responsive to the facilitating actions of brain progesterone.

The absence of ventricular involvement in mediating the behavioral effects of hormones placed in the central nervous system has been observed in other species. In ovariectomized rabbits, implants of estradiol benzoate in the third ventricle less than $1 \mathrm{~mm}$ from maximally responsive neural sites did not induce sexual receptivity ${ }^{38}$. Stilbestrol di-n-butyrate was ineffective when implanted into the ventricle of ovariectomized cats, but did reinstate behavioral estrus when placed in adjacent hypothalamic tissue $^{35}$. Contrary to these reports and the present study, Kent and Liberman ${ }^{20}$ demonstrated that progesterone dissolved in oil and inserted into the lateral ventricle facilitated lordosis in estrogen-primed hamsters. However the quantity of hormone administered $(25 \mu \mathrm{g})$ far exceeded the amounts used here and may account for these discrepant results.

The possibility that progesterone entered the systemic circulation when placed directly into the brain was not assessed in this investigation. However there are reasons to believe that the behavioral effects of brain progesterone were not mediated in this fashion. It would seem reasonable that the likelihood of any hormone gaining access 

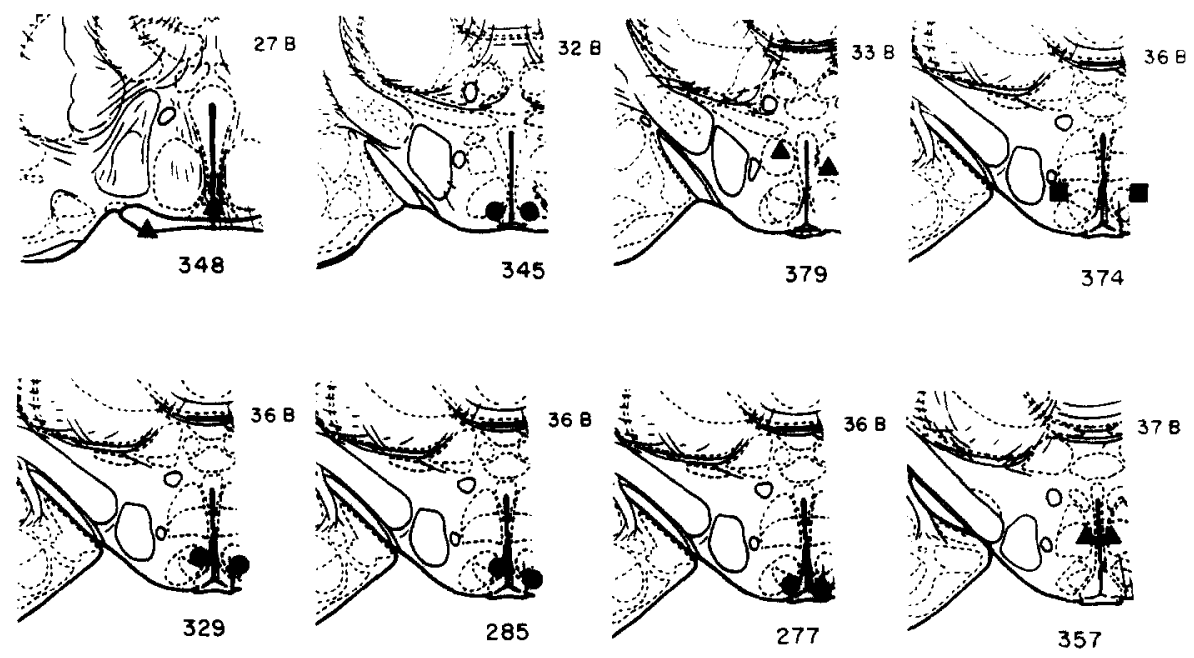

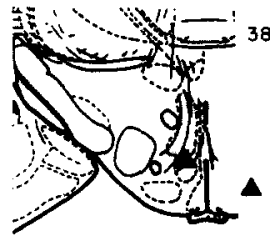

278

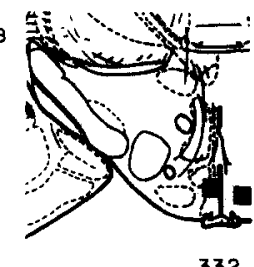

332

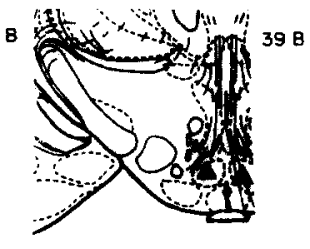

279

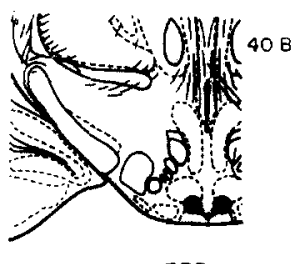

333
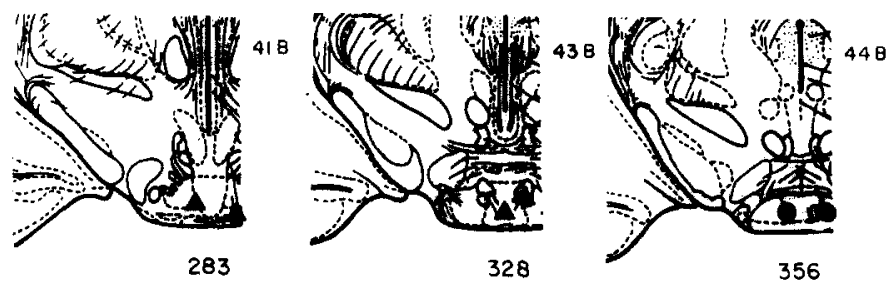

- HIGH RESPONOERS

MODERATE

RESPONDERS

A - LOW RESPONDERS

Fig. 3.

to the general circulation would be positively correlated with the relative vascularity of the implant site. In the rat, the least vascular area of the entire central nervous system is the region in which progesterone most effectively facilitated behavioral estrus $^{61}$. If progesterone influenced receptive behavior via the systemic circulation by activating cells outside the VM-ARC area, it would seem that the richer vascular bed of MRF cells should have provided more favorable conditions for such an action to occur; this obviously was not the case since MRF sites were minimally responsive to progesterone.

The consistency with which progesterone implants outside the ventromedial or arcuate nuclei failed to exert pronounced effects on receptivity (Fig. 3) suggests that passive diffusion of hormone throughout a wide zone of neural tissue did not 

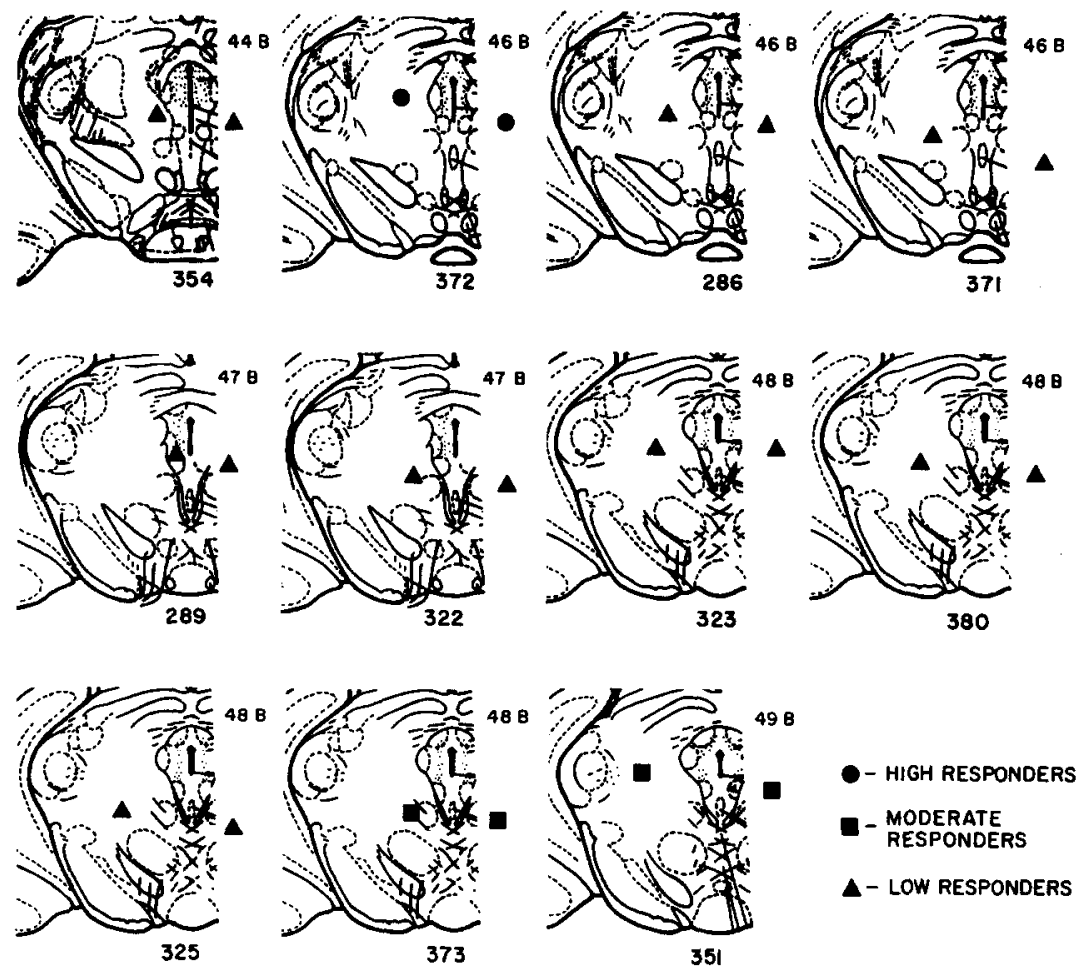

Figs. 3 and 4. Coronal sections adapted from König and Klippel ${ }^{25}$ indicating the localization of cannulae in females with MBH (Fig. 3) and MRF (Fig. 4) implants and the associated facilitation of sexual receptivity by intracerebral progesterone. Upper numbers refer to section designations in the atlas and lower numbers denote individual animals. Corrected progesterone facilitation scores were $0.0-0.5,0.6-1.0$ and 1.1 and above, for the low, moderate, and high responders, respectively.

occur. This is indirectly supported by measures of estrogen diffusion from hypothalamic implants; crystalline estradiol in 27-gauge MBH cannulae diffused only 1.0-2.0 $\mathrm{mm}$ from the implant site within $4-5$ days ${ }^{37}$. Although the diffusion characteristics of progesterone and estradiol in brain may be very different, it is unlikely that behaviorally significant amounts of progesterone diffused more than $0.5-1.0 \mathrm{~mm}$ from the cannula tips in the present study because cannulae remained in the brain for only $6 \mathrm{~h}$. Additionally, in studies concerned with other aspects of reproductive function, progesterone implants $1.5-2.0 \mathrm{~mm}$ from effective sites have remained in the brain for a much longer period of time without exerting positive effects suggesting that significant diffusion did not occur ${ }^{9,21,51}$.

There is some possibility that the central effects of progesterone identified in this study were mediated by ACTH-induced adrenal progesterone release. It is known that this source of progesterone facilitates behavioral estrus in estrogen-primed rodents ${ }^{11}$. The general stress associated with insertion of cannulae and its consequent stimulation of ACTH could not have been an important factor influencing 
the present results because insertions of both cholesterol and progesterone were presumably equally stressful. Because brain progesterone was considered facilitatory only when its associated level of receptivity was higher than that attributable to the cholesterol implant, a factor other than stress-induced adrenal progesterone had to be involved. Even the severe stress of general anesthesia does not facilitate sexual receptivity in rats primed with physiological quantities of estradiol ${ }^{41}$, although the timing of critical events during the estrous cycle may be related to the actions of adrenal progesterone ${ }^{10,36}$.

The results obtained in the present study failed to confirm that mesencephalic reticular formation implants of progesterone facilitate behavioral estrus in rats ${ }^{46}$. Histological analysis of cannula placements in the Ross et al. ${ }^{46}$ report indicated a rather widespread midbrain area was sensitive to progesterone although individual variability in progesterone responsiveness was not reported. Generally, the cannula placements tended to be more ventral and closer to the interpeduncular nucleus than those reported here. It seems unlikely that the present failure to show midbrain facilitation is related to differences in cannula location in the dorsal-ventral plane between the Ross et al. ${ }^{46}$ report and this study, and a consequent failure of implanted progesterone to reach sensitive sites at the base of the brain. This is because the one animal in the present investigation which did show progesterone facilitation in the MRF (Fig. 4, No. 372) had the most dorsal of all cannula placements. It is of course possible that a number of discrete regions within the midbrain are sensitive to progesterone and that the majority of implants were not sufficiently close to these focal points of hormone responsiveness to yield facilitating effects. Interestingly, the one MRF female which did respond to implanted progesterone had its cannulae located close to a region having some affinity for estrogen ${ }^{53}$.

The ineffectiveness of progesterone implants in the VM-ARC area of the hypothalamus reported by Ross et al. ${ }^{46}$ may be related to their use of unilateral implants. If bilateral exposure of relevant brain sites to progesterone is necessary to obtain significant behavioral effects on receptivity, then such effects would be minimized in areas where barriers exist to diffusion across the midline. The third ventricle in the hypothalamus could act as such a barrier whereas this would not be the case in the ventral mesencephalic reticular formation. It should be noted however that other behavioral actions of gonadal steroids can be effected by unilateral cannulae implants in the hypothalamus ${ }^{57}$.

The failure to find behavioral effects of progesterone implants in the MRF may appear surprising in view of the fact that this midbrain region shows a higher affinity for radioactive progesterone or its metabolites than does the hypothalamus in both the rat ${ }^{58,59}$ and guinea pig ${ }^{56}$. Although an earlier study reported that progesterone was retained in the hypothalamus significantly longer than in the brain stem ${ }^{14}$, it is difficult to know how comparable the midbrain and brain stem samples were in these studies. Autoradiographic analysis of progesterone uptake in neural tissue has not been reported but there seems little doubt that progesterone is taken up by a wide variety of brain structures $14,47-49,56,58,59$. The retention of progesterone by any particular brain region identifies it as a possible locus of functional significance in the 
hormone's mechanism of action, but additional types of corroborative information are necessary before definitive analysis becomes possible.

The brain areas identified in the present work as responsive to the behaviorfacilitating actions of progesterone are the same sites at which progesterone affects other reproductive functions. Ovulation can be facilitated ${ }^{9,21}$, or inhibited ${ }^{51}$ by progesterone implants in the medial basal hypothalamus but other targets in the brainpituitary-gonad axis may also be involved in these effects ${ }^{26,27}$. It has been suggested that progesterone facilitates ovulation by acting on the medial preoptic area ${ }^{4,54}$ or at other central sites more distant from the $\mathbf{M B H}^{17}$, but additional evidence suggests that such facilitation may be produced by altering thresholds in the $\mathrm{MBH}$ to nerve impulses originating in or passing through the $\mathrm{MPOA}^{9,22}$. However some types of progesterone receptors may exist in the anterior hypothalamus-preoptic area since pseudopregnancy can be induced in gonadally intact rats by progesterone implants in that region ${ }^{40}$.

Estradiol but not progesterone is essential for induction of lordosis in ovariectomized rats ${ }^{8}$. It might be expected that destruction of brain regions sensitive to the estrus-inducing actions of estrogen (MPOA) ${ }^{29}$ would disrupt receptivity to a greater extent than lesions in the progesterone-sensitive neural system (MBH). However just the opposite appears to be the case. Lesions of the MPOA do not interfere with mating behavior in the female rat ${ }^{28,50}$ and may increase rather than decrease sensitivity to estrogen ${ }^{43}$. Contrary to this effect, receptivity levels following exogenous hormones are considerably reduced after lesions in the vicinity of the ventromedial nucleus $(V M N)^{12,19,28}$. Similar deficits in estrous behavior which have been observed following anterior hypothalamic $(\mathrm{AH})$ lesions ${ }^{13,50}$ may be accounted for by noting that the neural regions damaged included portions of the VMN whereas other more rostral AH lesions which did not significantly affect the display of behavioral estrus ${ }^{19,28}$ involved little or no damage to the VMN. Interestingly, lesions in the caudal portion of the anterior hypothalamic nucleus produce massive terminal degeneration in the VMN whereas destruction of more rostral sites does not have this effect ${ }^{5}$. The present findings suggest that disruption of female mating behavior by VMN lesions may result from interference with a progesterone sensitive neural system in the medial basal hypothalamus.

It has been proposed that progesterone acts in a disinhibitory fashion with regard to sex behavior by decreasing functional activity in a system which tonically suppresses lordosis $^{7,33}$. This hypothesis is inconsistent with the fact that MBH lesions prevent the elicitation of receptive behavior. If progesterone facilitated the display of lordosis by suppressing neural activity in the $\mathrm{MBH}$, it would follow that estrogen alone, or estrogen plus subthreshold quantities of progesterone should be capable of inducing heat in rats with $\mathrm{MBH}$ lesions. However, this is not the case ${ }^{19,28}$ and suggests that progesterone affects estrous behavior in the rat by facilitating rather than inhibiting neural activity in the medial basal hypothalamus. Although the belief that progesterone acts to inhibit neural activity derives in part from the fact that this steroid can act as a general anesthetic ${ }^{39}$ and the abundant electrophysiological evidence demonstrating suppression of CNS activity following progesterone stimulation ${ }^{2,24,45}$, 
55 , there is little correlation between the estrus-facilitating actions and anesthetic properties of various progestational compounds ${ }^{34}$. In addition, the administration of progesterone to estrogen-primed female rats increases multiunit activity in the $\mathrm{MBH}$ with a latency which is comparable to the time when receptive behavior appears under these hormonal conditions ${ }^{55}$. Although it is always difficult to infer neuroanatomical specificity of hormone action based on electrophysiological evidence ${ }^{23}$, the findings of Terasawa and Sawyer ${ }^{55}$ are consistent with a facilitatory effect of progesterone on $\mathrm{MBH}$ neurons which may constitute an important component of the neural mechanisms regulating estrous behavior in the rat.

SUMMARY

Ovariectomized female rats were estrogen-primed by subcutaneous injection and two days later were tested for sexual receptivity $6 \mathrm{~h}$ following bilateral implants of crystalline progesterone or cholesterol combined with a subthreshold injection of progesterone administered systemically. Cannulae were located in either the medial basal hypothalamus $(\mathrm{MBH})$ or the mesencephalic reticular formation (MRF) in different groups of females.

Significant facilitation of estrous behavior was induced by brain progesterone in females whose cannulae were located in the MBH. Intracerebral progesterone was not effective in females with MRF cannulae. Within the MBH the ventromedial and arcuate nuclei appeared most responsive to the estrus-facilitating actions of progesterone. The possibility that the behavioral effects of implanted progesterone were mediated by entry of hormone into the ventricular system or general circulation is considered unlikely. It is suggested that progesterone facilitates lordosis behavior via a facilitatory rather than an inhibitory effect on $\mathrm{MBH}$ neurons.

\section{ACKNOWLEDGEMENTS}

Research supported by NIMH Grant No. MH20811 to Elliot S. Valenstein. I wish to thank Irving Zucker for his multifaceted support throughout the initial stages of this work, and Elliot Valenstein for valuable discussion and criticism of the manuscript. Patti Soffer, Muriel Nathan, Linda Zuckerman and Maureen Powers provided excellent surgical, behavioral, and histological assistance.

\section{REFERENCES}

1 Anderson, C. H., ANd Greenwald, G. S., Autoradiographic analysis of estradiol uptake in the brain and pituitary of the female rat, Endocrinology, 85 (1969) 1160-1165.

2 ARAi, Y., HiroI, M., Mitra, J., AND GorSKI, R. A., Influence of intravenous progesterone administration on the cortical electroencephalogram of the female rat, Neuroendocrinology, 2 (1967) 275-282.

3 Attramadal, A., Cellular localization of [ $\left.{ }^{3} \mathrm{H}\right]$ loestradiol in the hypothalamus: An autoradiographic study in male and female rats, $Z$. Zellforsch., 104 (1970) 572-581.

4 Barraclough, C. A., Yrarrazaval, S., and Hatton, R., A possible hypothalamic site of action of progesterone in the facilitation of ovulation in the rat, Endocrinology, 75 (1964) 838-845.

Brain Research, 48 (1972) 311-325 
5 CHI, C. C., Afferent connections to the ventromedial nucleus of the hypothalamus in the rat, Brain Research, 17 (1970) 439-445.

6 CiAccio, L. A., AND Lisk, R. D., Hormonal control of cyclic estrus in the female hamster, Amer. J. Physiol., 221 (1971) 936-942.

7 Clemens, L. G., Wallen, K., AND Gorski, R. A., Mating behavior: Facilitation in the female rat after cortical application of potassium chloride, Science, 157 (1967) 1208-1209.

8 Davidson, J. M., Rodgers, C. H., Smith, E. R., ANd Bloch, G. J., Stimulation of female sex behavior in adrenalectomized rats with estrogen alone, Endocrinology, 82 (1968) 193-195.

9 DOCKE, F., AND DORNER, G., A possible mechanism by which progesterone facilitates ovulation in the rat, Neuroendocrinology, 4 (1969) 139-149.

10 Feder, H. H., Brown-Grant, K., and Corker, C. S., Pre-ovulatory progesterone, the adrenal cortex and the 'critical period' for luteinizing hormone release in rats, J. Endocr., 50 (1971) 29-39.

11 FEDER, H. H., AND RUF, K. B., Stimulation of progesterone release and estrous behavior by ACTH in ovariectomized rodents, Endocrinology, 84 (1969) 171-174.

12 Goy, R. W., And Phoenix, C. H., Hypothalamic regulation of female sexual behaviour; Establishment of behavioural oestrus in spayed guinea-pigs following hypothalamic lesions, J. Reprod. Fertil., 5 (1963) 23-40.

13 Greer, M. A., The effect of progesterone on persistent vaginal estrus produced by hypothalamic lesions in the rat, Endocrinology, 53 (1953) 380-390.

14 Hamburg, D. A., Effects of progesterone on behavior, Res. Publ. Ass. nerv. ment. Dis., 43 (1966) 251-265.

15 HaRdy, D. F., AND DeBold, J. F., Effects of mounts without intromission upon the behavior of female rats during the onset of estrogen-induced heat, Physiol. Behav., 7 (1971) 643-645.

16 JosLyn, W. D., Feder, H. H., AND GoY, R. W., Estrogen conditioning and progesterone facilitation of lordosis in guinea pigs, Physiol. Behav., 7 (1971) 477-482.

17 KaAsjager, W. A., Woodbury, D. M., van Dieten, J. A. M., and van Rees, G. P., The role played by the preoptic region and the hypothalamus in spontaneous ovulation and ovulation induced by progesterone, Neuroendocrinology, 7 (1971) 54-64.

18 Kendall, J. W., Grimm, Y., and Shimshak, G., Relation of cerebrospinal fluid circulation to the ACTH-suppressing effects of corticosteroid implants in the rat brain, Endocrinology, 85 (1969) 200-208.

19 KenNedy, G. C., Hypothalamic control of the endocrine and behavioral changes associated with oestrus in the rat, J. Physiol. (Lond.), 172 (1964) 383-392.

$20 \mathrm{KENT}$, G. C., AND LiBerman, M. J., Induction of psychic estrus in the hamster with progesterone administered via the lateral brain ventricle, Endocrinology, 45 (1949) 29-32.

21 Kobayashi, F., Hara, F., AND Miyake, T., Facilitation of luteinizing hormone release by progesterone in proestrous rats, Endocr. jap., 17 (1970) 149-155.

22 Kobayashi, F., and MiyaKe, T., Acute effect of hypothalamic deafferentation on progesteroneinduced ovulating hormone release in the rats, Endocr. jap., 18 (1971) 395-401.

23 Komisaruk, B. R., Strategies in neuroendocrine neurophysiology, Amer. Zool, 11 (1971) 741-754.

24 Komisaruk, B. R., MCDonald, P. G., Whitmoyer, D. I., and Sawyer, C. H., Effects of progesterone and sensory stimulation on EEG and neuronal activity in the rat, Exp. Neurol., 19 (1967) 494-507.

25 KönIG, J. F. R., AND Klippel, R. A., The Rat Brain: A Stereotaxic Atlas of the Forebrain and Lower Parts of the Brain Stem, Williams and Wilkens, Baltimore, 1963.

26 LABHSETwAR, A. P., Exploration of site(s) of action of progesterone in inhibiting ovulation in rats, Biol. Reprod., 5 (1971) 115-122.

27 LABHSETwaR, A. P., AND BAINBRIDge, J. G., Inhibition of ovulation by intracranial implantation of progesterone in the 4-day cyclic rat, J. Reprod. Fertil., 27 (1971) 445-449.

28 LaW, T., ANd Meagher, W., Hypothalamic lesions and sexual behavior in the female rat, Science, 128 (1958) 1626-1627.

29 LISK, R. D., Diencephalic placement of estradiol and sexual receptivity in the female rat, Amer. J. Physiol., 203 (1962) 493-496.

30 Lisk, R. D., Sexual behavior: hormonal control. In L. MArTini ANd W. F. Ganong (Eds.), Neuroendocrinology, Vol. 2, Academic Press, New York, 1967, pp. 197-239.

31 Lisk, R. D., AND SuYdam, A. J., Sexual behavior patterns in the prepubertally castrate rat, Anat. Rec., 157 (1967) 181-190.

32 Meyerson, B. J., The effect of neuropharmacological agents on hormone-activated estrus behaviour in ovariectomized rats, Arch. int. Pharmacodyn., 150 (1964) 4-33. 
33 MEYERSON, B. J., Estrus behaviour in spayed rats after estrogen or progesterone treatment in combination with reserpine or tetrabenazine, Psychopharmacologia (Berl.), 6 (1964) 210-218.

34 Meyerson, B. J., Relationship between the anesthetic and gestagenic action and estrous behavior-inducing activity of different progestins, Endocrinology, 81 (1967) 369-374.

35 Michael, R. P., Oestrogens in the central nervous system, Brit. med. Bull., 21 (1965) 87-90.

36 Nequin, L. G., AND Schwartz, N. B., Adrenal participation in the timing of mating and LH release in the cyclic rat, Endocrinology, 88 (1971) 325-331.

37 Palka, Y. S., Ramirez, V. D., AND Sawyer, C. H., Distribution and biological effects of tritiated estradiol implanted in the hypothalamo-hypophysial region of female rats, Endocrinology, 78 (1966) 487-499.

38 Palka, Y. S., ANd Sawyer, C. H., The effects of hypothalamic implants of ovarian steroids on oestrous behaviour in rabbits, J. Physiol. (Lond.), 185 (1966) 251-269.

39 P'An, S., And Laubach, G. D., Steroid central depressants. In R. I. Dorfman (Ed.), Methods in Hormone Research, Vol. 3, Academic Press, New York, 1964, pp. 415-475.

40 Pasteels, J.-L., AND Ectors, F., Identical localization of oestrogen- and progestagen-sensitive hypothalamic areas. In P. O. Hubinont, F. Leroy And P. Galand (Eds.), Basic Actions of Sex Steroids on Target Organs, Karger, Basel, 1971, pp. 200-207.

41 Powers, J. B., Hormonal control of sexual receptivity during the estrous cycle of the rat, Physiol. Behav., 5 (1970) 831-835.

42 Powers, J. B., Hormonal regulation of sexual receptivity in the female rat, Diss. Abstr. Int. (B), 32 (1971) 767-B.

43 Powers, J. B., And Valenstein, E. S., Sexual receptivity: Facilitation by medial preoptic lesions in female rats, Science, 175 (1972) 1003-1005.

44 POWERS, J. B., AND VALENSTEIN, E. S., Individual differences in sexual responsiveness to estrogen and progesterone in ovariectomized rats, Physiol. Behav., 8 (1972) 673-676.

45 Ramirez, V. D., Komisaruk, B. R., Whitmoyer, D. I., and SawYer, C. H., Effects of hormones and vaginal stimulation on the EEG and hypothalamic units in rats, Amer. J. Physiol., 212 (1967) $1376-1384$.

46 Ross, J., Claybaugh, C., Clemens, L. G., and Gorski, R. A., Short latency induction of estrous behavior with intracerebral gonadal hormones in ovariectomized rats, Endocrinology, 89 (1971) 32-38.

47 Seiki, K., AND Hattori, M., A more extensive study on the uptake of labelled progesterone by the hypothalamus and pituitary gland of rats, J. Endocr., 51 (1971) 793-794.

48 Seiki, K., Higashida, M., Imanishi, Y., Miyamoto, M., Kitagawa, T., and Kotani, M., Radioactivity in the rat hypothalamus and pituitary after injection of labelled progesterone, J. Endocr., 41 (1968) 109-110.

49 Seiki, K., Miyamoto, M., Yamashita, A., and Kotani, M., Further studies on the uptake of labelled progesterone by the hypothalamus and pituitary of rats, J. Endocr., 43 (1969) 129-130.

50 Singer, J. J., Hypothalamic control of male and female sexual behavior in female rats, J. comp. physiol. Psychol., 66 (1968) 738-742.

51 SMith, E. R., Weick, R. F., ANd DAVIDSON, J. M., Influence of intracerebral progesterone on the reproductive system of female rats, Endocrinology, 85 (1969) 1129-1136.

52 STUMPF, W. E., Estrogen-neurons and estrogen-neuron systems in the periventricular brain, Amer. J. Anat., 129 (1970) 207-218.

53 STUMPF, W. E., Hypophyseotropic neurons in the periventricular brain: topography of estradiol concentrating neurons. In C. H. SAWYER AND R. H. GORSKI (Eds.), Steroid Hormones and Brain Function, UCLA Forum in the Medical Sciences, No. 15, Univ. of California Press, Los Angeles, 1971, pp. 215-226.

54 Taleisnik, S., Velasco, M. E., AND Astrada, J. J., Effect of hypothalamic deafferentation on the control of luteinizing hormone secretion, $J$. Endocr., 46 (1970) 1-7.

55 Terasawa, E., AND Sawyer, C. H., Diurnal variation in the effects of progesterone on multiple unit activity in the rat hypothalamus, Exp. Neurol., 27 (1970) 359-374.

56 WADE, G. N., AND FEDER, H. H., $\left[1,2^{3} \mathrm{H}\right]$ Progesterone uptake by guinea pig brain and uterus: Differential localization, time-course of uptake and metabolism, and effects of age, sex, estrogenpriming and competing steroids, Brain Research, 45 (1972) 525-543.

57 WADE, G. N., AND ZUCKER, I., Modulation of food intake and locomotor activity in female rats by diencephalic hormone implants, J. comp. physiol. Psychol., 72 (1970) 328-336.

58 Whalen, R. E., AND Luttge, W. G., Role of the adrenal in the preferential accumulation of progestin by mesencephalic structures, Steroids, 18 (1971) 141-146.

Brain Research, 48 (1972) 311-325 
59 Whalen, R. E., ANd Luttge, W. G., Differential localization of progesterone uptake in brain. Role of sex, estrogen pretreatment and adrenalectomy, Brain Research, 33 (1971) 147-155.

60 Young, W. C., The hormones and mating behavior. In W. C. Young (Ed.), Sex and Internal Secretions, Vol. 2, Williams and Wilkins, Baltimore, 1961, pp. 1173-1239.

61 ZEMan, W., AND InNes, J. R. M., Craigie's Neuroanatomy of the Rat, Academic Press, New York, 1963 , p. 35. 